\title{
Surface modification on PMMA : PVDF polyblend: hardening under chemical environment
}

\author{
R BAJPAI*, V MISHRA, PRAGYESH AGRAWAL ${ }^{\dagger}$ and S C DATT \\ Department of Postgraduate Studies and Research in Physics, Rani Durgavati University, Jabalpur 482 001, India \\ ${ }^{\dagger}$ Department of Physics, St. Aloysius College, Jabalpur 482 001, India
}

MS received 29 May 2001; revised 29 December 2001

\begin{abstract}
The influence of chemical environment on polymers include the surface alteration as well as other deep modifications in surface layers. The surface hardening, as an effect of organic liquids on poly(methyl methacrylate): poly(vinylidene fluoride) (PMMA: PVDF), which is one of the few known miscible blends, has been detected using microhardness testing. Organic liquids like acetone, toluene, xylene and benzene were introduced on the surface of blend specimens for different durations. Vickers microhardness $\left(H_{v}\right)$ was measured for treated and untreated specimens. The study reveals both hardening and plasticization of specimens at different exposure times. The degree of surface hardening is maximum under acetone treatment. All the specimens exhibit surface hardening at an exposure time of $1 \mathrm{~h}$ with all the four liquids. This feature is prominent with longer exposures for specimens with increasing content of PVDF. However, the degree of hardening decreases with the time of exposure in the respective environments. In general, acetone and toluene impart surface hardening, whereas, xylene and benzene soften the specimen. PMMA: PVDF (83 : 17) blend exhibits surface hardening under all the four treatments when compared with the respective untreated specimens.
\end{abstract}

Keywords. Polyblend; surface modification; microhardness; hardening; plasticization; segmental mobility.

\section{Introduction}

Polymeric materials have a specific feature of stability towards various aggressive chemical environments, which depends on a multiplicity of factors like structure and nature of the polymers and chemical media as well as on the time and temperature of exposure. The influence of chemical environment on polymers include the surface alteration as well as other deep modifications in surface layer (Lashkov et al 1986; Krupenya et al 1988, 1989). The studies on environmentally affected mechanical behaviour of polymers are reported by several workers (Kojima and Satake 1984; Omar et al 1986; Wu and Brown 1986; Pandey et al 1990; Maccone et al 2000). The controlling of process parameters and use of different solvents allowed the preparation of combined materials having specified levels of resistance. Fluoropolymers have also been regarded as outstanding polymers for applications where a chemical environment and high temperature are dominating factors. Among fluoropolymers, poly(vinylidene fluoride) (PVDF) exhibits the highest mechanical strength coupled with fairly good chemical resistance (Ajroldi 1997). Poly(methyl methacrylate) (PMMA) is a well known polymer which is hard

\footnotetext{
*Author for correspondence
}

and transparent with good outdoor weathering. The miscibility of PMMA: PVDF has been reported (Nishi and Wang 1975; Paul and Altamirano 1975). The present paper reports the study on the surface modification of PMMA: PVDF blend system under chemical environment of some organic liquids. The tool used for detection is Vickers microhardness technique. This technique is now being utilized widely for morphological stabilization and plasticization studies of polymers (Gonzalez et al 1986; Pandey et al 1990; Bajpai et al 1992; Mishra et al 1994).

\section{Experimental}

\subsection{Preparation of blends}

The powders of PMMA (BDH, UK) and PVDF (Aldrich, USA) were supplied by M/s Chemical Agencies, Mumbai, India. The quoted values of molecular weights are 5,00,000 and 3,50,000; glass transition temperatures, 105 and $13^{\circ} \mathrm{C}$; melting temperatures, 225 and $171^{\circ} \mathrm{C}$ and specific gravities, 1.19 and 1.8 , respectively. The solution cast technique was utilized for preparing the blends. PMMA and PVDF were taken in suitable and definite compositional ratios and were dissolved in an appropriate amount of dimethylformamide. The solution was then heated in a thermostatically controlled electric oven at a temperature of $110^{\circ} \mathrm{C}$ for $3 \mathrm{~h}$. The oven was then switched off and the 
glass mould along with the solution was given sufficient time to cool down (nearly $24 \mathrm{~h}$ ). Samples of $1 \mathrm{sq} \mathrm{cm}$ size and $0.05 \mathrm{~cm}$ thickness were cut from the pellets for the chemical treatment.

\subsection{Chemical treatment}

Organic liquids viz. benzene, toluene, xylene and acetone, were introduced onto the indentation area from a clean glass syringe at the beginning of each test and in the cases, where rapid evaporation occurred (e.g. acetone), more liquid was delivered from the syringe during the course of indentation so that the test area was always flooded. These liquids were poured onto the surface for a definite time period, after which the liquid was sucked out with the help of blotting paper.

\subsection{Analytical method}

The blend specimens were indented at room temperature by Vickers diamond pyramidal indenter attached to Carl-

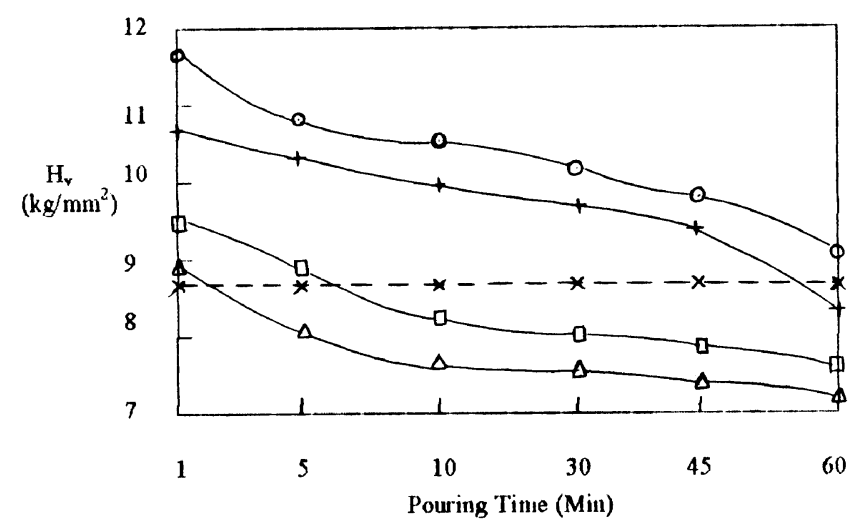

Figure 1. Variation of $H_{\mathrm{v}}$ with pouring time for blend specimens with $95: 5 \mathrm{wt} \%$ ratio: $\times$, untreated; o, acetone; +, toluene; $\square$, xylene and $\Delta$, benzene.

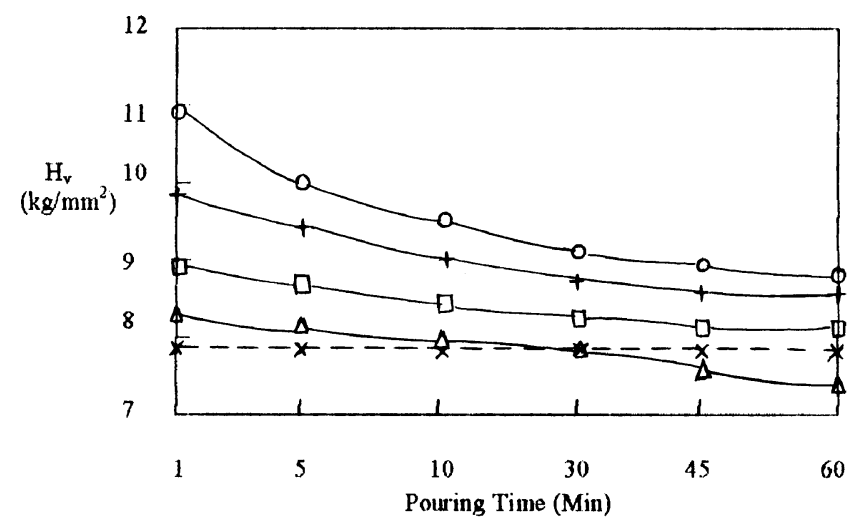

Figure 2. Variation of $H_{\mathrm{v}}$ with pouring time for blend specimens with $91: 9 \mathrm{wt} \%$ ratio: $\times$, untreated; 0 , acetone; + , toluene; $\square$, xylene and $\Delta$, benzene.
Zeiss NU-2 microscope. The specimens were indented at the load of $80 \mathrm{~g}$. The diameter of indentations were measured using a micrometer eyepiece. For each test the duration of indentation was $30 \mathrm{~s}$. For each load at least five indentations were made at different points of the specimens and average hardness number was calculated. The Vickers hardness number, $H_{\mathrm{v}}$, was calculated from the relation:

$$
H_{\mathrm{v}}=(1.854 \times L) / d^{2} \mathrm{~kg} / \mathrm{mm}^{2},
$$

where $L$ is load and $d$ the length of diagonal of indentation in $\mathrm{mm}$.

\section{Results and discussion}

Figures 1-4 illustrate the decreasing nature of the level of $H_{\mathrm{v}}$ of PMMA: PVDF blends having different PVDF contents $(5,9,13$ and $17 \mathrm{wt} \%)$ with increasing pouring time for different chemical environments. Figure 1 depicts the variation of $H_{\mathrm{v}}$ level of $95: 5$ blend. It is observed that the $H_{\mathrm{v}}$ level is different for blend specimens treated under different chemical environments. The $H_{\mathrm{v}}$ level is found to decrease with increasing pouring time for all chemically treated blend specimens. This agrees with the fact that the small amount of plasticizer always increases the strength (Tager 1978; Mishra et al 1994). The level of $H_{\mathrm{v}}$ is highest under acetone environment and lowest in case of benzene environment amongst the organic liquids studied. For acetone environment, the $H_{\mathrm{v}}$ profile is such that there is a sharp decrease in $H_{\mathrm{v}}$ level for the 1-5 min duration of exposure and remarkably less change is observed between the 5 and 45 min exposure, beyond which the level of $H_{\mathrm{v}}$ decreases sharply again. The higher $H_{\mathrm{v}}$ levels at all pouring time under acetone environment than that of untreated ones, suggest the occurrence of surface hardening. The degree of hardening tends to decrease with increasing time of exposure. Toluene environment also hardens the blend specimens up to the pouring time of $45 \mathrm{~min}$. The

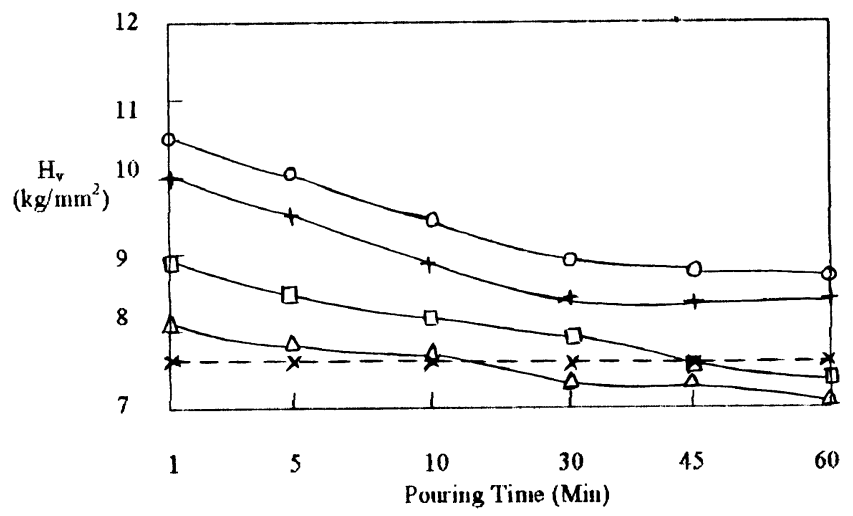

Figure 3. Variation of $H_{\mathrm{v}}$ with pouring time for blend specimens with $87: 13 \mathrm{wt} \%$ ratio: $\times$, untreated; 0 , acetone; + , toluene; $\square$, xylene and $\Delta$, benzene. 


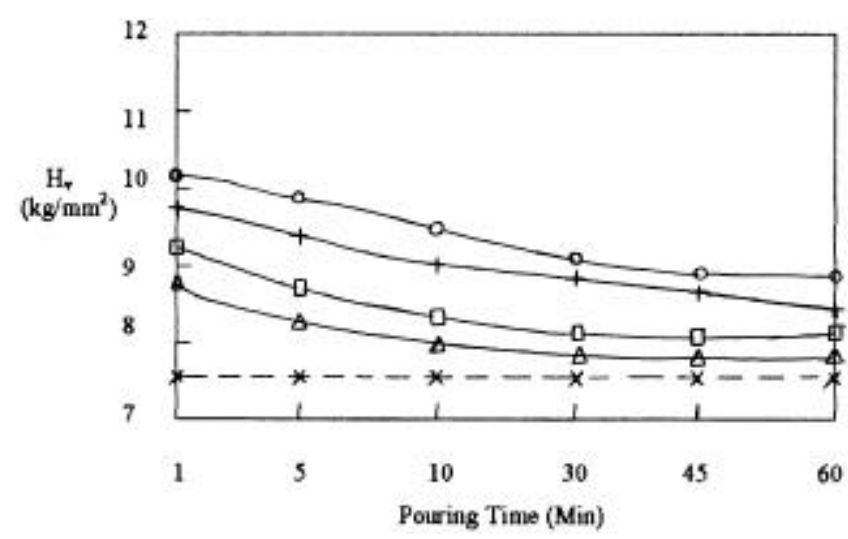

Figure 4. Variation of $H_{\mathrm{v}}$ with pouring time for blend specimens with $83: 17$ wt $\%$ ratio: $\times$, untreated; 0 , acetone; + , toluene; $\square$, xylene and $\Delta$, benzene.

treatment under benzene environment produces greater plasticization effect after the pouring time of $1 \mathrm{~min}$. The $H_{\mathrm{v}}$ values of blend specimens treated under xylene environment for more than $5 \mathrm{~min}$ are found to be lower than the untreated specimen.

Figure 2 depicts that the treatments of $91: 9$ blend with acetone, toluene and benzene induce the surface hardening even up to the exposure time of $1 \mathrm{~h}$. In case of xylene environment the blend specimens are hardened up to the exposure time of $30 \mathrm{~min}$, thereafter the plasticization is observed.

Figure 3 illustrates the surface hardening of $87: 13$ blend at all pouring times in case of acetone and toluene environments while for xylene and benzene environments the hardening is limited up to the exposure time of $10 \mathrm{~min}$. Beyond $30 \mathrm{~min}$, exposure under xylene and benzene gives rise to plasticization which increases with increasing exposure time.

Figure 4 also depicts the surface hardening in case of all organic liquids studied at all pouring times and no plasticization is seen in the $83: 17$ blend, however, the degree of hardening is different for different environments. Moreover, the degree of hardening is becoming less as the exposure time is increased. This blend having the highest PVDF content, in the present investigation and where the highest softening is observed in absence of any treatment reported elsewhere (Bajpai et al 1992) shows a tendency of surface hardening under organic media.

The decrease in the level of $H_{\mathrm{v}}$ on increasing plasticizer content or pouring time is due to increasing chain segmental mobility (Elias 1984). Since PVDF is miscible with PMMA, hence on adding, it increases the segmental mobility of chains which results in the fall in the level of $H_{\mathrm{v}}$. The anomalies, which are observed with lower plasticizer content or pouring time, are often due to antiplasticization, which is caused by eradication of defects in the polymers (Tager 1978; Elias 1984). The ability of a liquid to plasticize a polymer depends on the difference in their respective values of the solubility parameter; the smaller the difference the greater the degree of plasticization (Pandey et al 1990).

\section{Conclusions}

It can be concluded that the environment of acetone causes overall surface hardening for all blend specimens. Environments of toluene, xylene and benzene harden the blend specimens at smaller exposure times and plasticize the specimens for longer exposures. Moreover, with increase in PVDF content in PMMA matrix, this influence weakens and for blend specimens with maximum wt\% $(17 \mathrm{wt} \%)$ no plasticization takes place even for $1 \mathrm{~h}$ pouring time.

\section{References}

Ajroldi 1997 Chim. Ind. (Milan) 79483

Bajpai R, Mishra V and Datt S C 1992 Polym. Test. 11 387

Elias H G 1984 Macromolecules, synthesis, materials and technology (New York: Plenum Press) Vol. 2, p. 1150

Gonzalez A, Martin G J, de Saja J A and Rodriguez R 1986 J. Appl. Polym. Sci. 31717

Kojima M and Satake H 1984 J. Polym. Sci. Polym. Phys. 22 285

Krupenya E N, Kagan A Yu and Simonov-Emel Yanov I D 1988 Int. Polym. Sci. Technol. 15 T/57

Krupenya E N, Kagan A Yu, Simonov-Emel Yanov I D, Kuleznez V N and Mukhina L L 1989 Int. Polym. Sci. Technol. $16 \mathrm{~T} / 55$

Lashkov G L, Veniaminov A V and Ratner O B 1986 Polym. Sci., URSS 28143

Maccone P, Brinatli G and Arcella V 2000 Polym. Eng. \& Sci. 40761

Mishra V, Bajpai R and Datt S C 1994 Polym. Test. 13435

Nishi T and Wang T T 1975 Macromolecules 8909

Omar M K, Atkins A G and Lancaster J K 1986 J. Mater. Sci. 212528

Pandey S, Bajpai R and Datt S C 1990 Polym. Test. 10111

Paul D R and Altamirano J O 1975 Adv. Chem. Ser. 142354

Tager A 1978 Physical chemistry of polymers (Moscow: Mir Publishers) p. 558

Wu J C B and Brown N J 1986 J. Mater. Sci. 211311 